\title{
Mechanisms governing the biphasic pattern of gastric emptying after truncal vagotomy and pyloroplasty
}

\author{
N J PARR, S GRIME, M CRITCHLEY, J N BAXTER, AND C R MACKIE \\ From the University Department of Surgery and Department of Nuclear Medicine, Royal Liverpool Hospital, \\ Liverpool
}

SUMMARY The pattern of gastric emptying after truncal vagotomy and drainage is usually biphasic. An early rapid phase is followed by a characteristically abrupt transition to slow emptying. The mechanisms responsible for this pattern were studied in six dogs with truncal vagotomy and pyloroplasty, fitted with a proximal duodenal cannula. Gastric emptying was measured using gamma camera imaging of a radiolabelled $15 \%$ dextrose test meal. Sixty one hour studies were done using five designs. (1) With the cannula closed gastric emptying was initially rapid, followed by stasis (emptying at $15 \mathrm{~min}-32 \%(5 \cdot 3), 60 \mathrm{~min}-34 \%(4 \cdot 8)$; mean (SE)). (2) With the cannula open emptying was very rapid $(15 \mathrm{~min}-76 \%(4 \cdot 2) \mathrm{p}<0.001,60 \mathrm{~min}-88 \%(2.6) \mathrm{p}<0.001$ ANOVA). (3) Distal duodenal instillation of isotonic saline, at a rate equivalent to gastric emptying with the cannula closed, did not retard this rapid emptying (15 min - 78\% (10.6), 60 min - 90\% (5.4)). (4) With duodenal instillation of $15 \%$ dextrose, gastric emptying remained faster than in studies without diversion (15 min $-50 \%(7 \cdot 0) \mathrm{NS}, 60 \mathrm{~min}-65 \%(6 \cdot 8) \mathrm{p}<0.01)$, but was slower than during diversion alone $(p<0.05)$. (5) Finally, duodenal instillation of $15 \%$ dextrose before administration of the test meal produced slower initial emptying without subsequent stasis (15 min - 24\% (4.5), 60 min - 47\% $(10 \cdot 6)$ ), although the amounts emptied were not significantly different from those with the cannula closed. These results indicate that after truncal vagotomy and pyloroplasty small bowel resistances play a significant role in controlling gastric emptying. Osmoreceptor responses persist after truncal vagotomy, but sympathetic inhibitory responses to small bowel distension are not involved in the regulatory process.

Patients with truncal vagotomy and drainage exhibit an abnormal pattern of gastric emptying of liquids. An initial phase of rapid emptying persists for 10-15 minutes from the beginning of meal ingestion..$^{1-3}$ This increase in initial emptying has been attributed both to section of vagal fibres responsible for gastric receptive relaxation, ${ }^{4}$ and to a reduction in gastric outflow resistance resulting from the gastric drainage procedure. ${ }^{5}$ After the initial rapid phase there is a transition to slower emptying and sometimes to stasis. This transition is characteristically abrupt. The mechanisms responsible for this change are uncertain, and could be of clinical importance because greater initial emptying is found in patients suffering

Address for correspondence: Mr N J Parr, Department of Surgery, Royal Liverpool Hospital, Prescot Street, Liverpool L7 8XP.

Received for publication 16 March 1988. from postvagotomy diarrhoea ${ }^{13}$ and from the dumping syndrome. ${ }^{6}$

We postulated that the transition from initial rapid to slower phase gastric emptying could take place in one or more of four ways. First, a rigid vagotomised stomach could contract rapidly to a predetermined volume, and then be unable to expel the remainder of a meal at the same rate. Second, the osmoreceptor response, which normally regulates the emptying rate of nutrients, could persist after truncal vagotomy and delay emptying after the initial rapid phase. Third, a period of initial rapid emptying could induce a resistance in the upper small bowel, opposing further gastric efflux. Finally distension of the upper small bowel caused by rapid initial emptying could stimulate tension receptors within its wall, and inhibit gastric emptying via the sympathetic nervous system. The aim of this study was to explore the importance 
of each of these possible mechanisms in the regulation of gastric emptying after truncal vagotomy and pyloroplasty in dogs.

The study was based on the assumption that opening a proximal duodenal cannula will release small bowel resistances to gastric emptying, while allowing distal instillation of test solutions to simulate volume and osmoreceptor stimuli to the small intestine.

\section{Methods}

\section{ANIMALS}

Six beagle bitches (weights $13-17 \mathrm{~kg}$ ) underwent transabdominal bilateral truncal vagotomy with a 3 $\mathrm{cm}$ Heinecke-Mikulitz pyloroplasty. Each animal also had a Thomas cannula inserted into the duodenum approximately $4 \mathrm{~cm}$ distal to the pylorus. Three of the dogs had a Dacron cuff sutured loosely around the duodenum, immediately distal to the cannula. No cuffing procedure was carried out in the remaining three dogs. The dogs were allowed 12 weeks to recover from operation before commencing studies. During this period all remained in good health and maintained their body weights.

The dogs were trained to stand in a Pavlov sling against a Nuclear Enterprises 8900 gamma camera. No sedatives were used. All food and drink was withheld overnight before each study day. For all studies $250 \mathrm{ml} 15 \%$ dextrose labelled with $10 \mathrm{MBq}$ ${ }^{99 m}$ Tc-DTPA was instilled into the stomach through an orogastric tube. Instillation took place in less than 90 seconds and the tube was then withdrawn. Imaging proceeded over 60 minutes with a one minute frame time. Analysis of the acquired scintigraphic data was as previously described, ${ }^{7}$ with intragastric time-activity curves being generated for the entire period of imaging.

Each dog had two studies with the cannula closed to assess reproducibility and daily variation in rates of gastric emptying. From the results of these studies the mean duration of the initial rapid phase and the mean amount emptied during this phase were calculated for each dog (Fig. 1). Thereafter, all studies were carried out with the cannula open and freely draining into a flask underneath the animal's abdomen. In all these studies a 12FG Foley catheter was inserted through and inflated just distal to the cannula. This allowed total diversion of gastric effluent through the cannula, and permitted instillation of test solutions into the duodenum distal to the occluding balloon. Instillation was done manually using a syringe (Fig. 2). Preliminary tests were carried out using methylene blue as a marker, to confirm that solutions could be instilled distally at a rapid rate without leakage back into the cannula. No

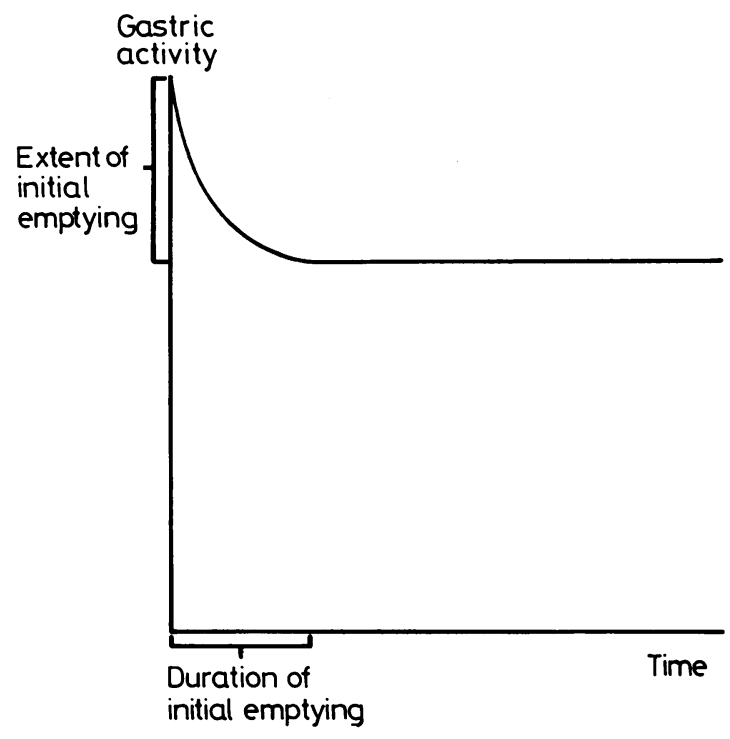

Fig. 1 For each dog the mean duration of the initial phase of gastric emptying, and the amount emptied during this time, were determined from duplicate studies with the cannula closed. In all subsequent studies test solutions were instilled into the small bowel at an identical rate.

leakage occurred, and the balloon volume required to achieve a satisfactory seal was similar for animals with and without the periduodenal Dacron cuff. Each animal was studied twice by each of four different test designs, carried out in a random order: (1) Without distal instillation of a test solution. In two of these studies the glucose concentration and the isotope activity of the effluent were measured and compared with those of the test meal. (2) With distal instillation of $0.9 \%$ saline in the same volume and at the same rate as that dog's mean gastric emptying calculated from its two studies with the cannula closed, and with instillation commencing at the same time as test meal



Fig. 2 Diagram of the experimental model. 


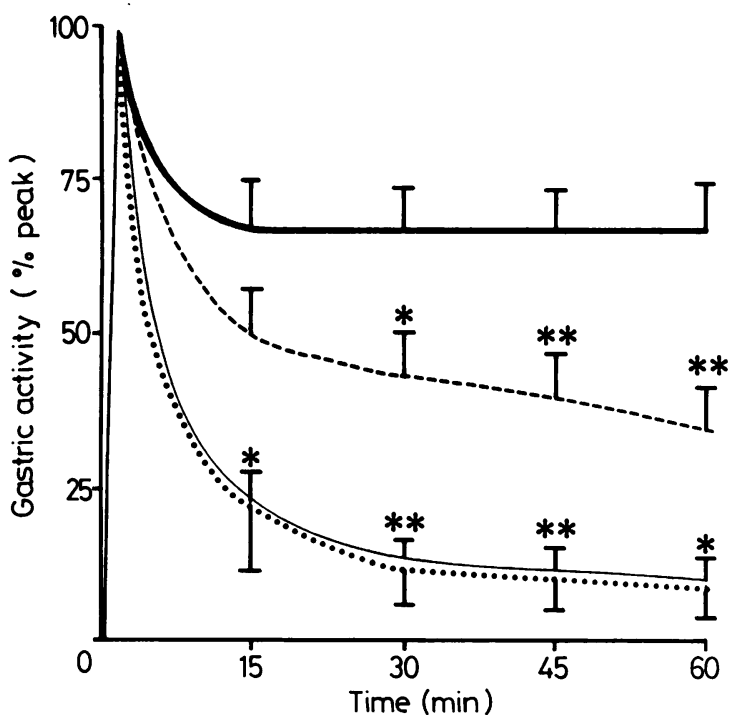

Fig. 3 Results of studies with the cannula closed (-), cannula open without distal instillation (-), open with isotonic saline instillation (...) and open with $15 \%$ dextrose instillation (---). Gastric activity, expressed as a percentage of peak gastric activity, is plotted on a linear scale against time. Curves represent mean values at 1 min intervals, and (SE) at 15 min intervals. Asterisks denote significant differences between adjacent curves (analysis of variance), ${ }^{*} p<0.05,{ }^{* *} p<0.01$.

administration. (3) With distal instillation of $15 \%$ dextrose in the same manner. (4) With distal instillation of $15 \%$ dextrose in the same volume and at the same rate, but preceding test meal administration by the duration of that animal's initial phase of rapid gastric emptying, observed in studies with the cannula closed.

Finally, a post mortem dissection was carried out on each animal to ensure that both vagal trunks had been divided.

\section{STATISTICAL ANALYSIS}

Comparisons of gastric emptying at 15 minute intervals during the five study designs were made using Analysis of Variance, computing the mean values from paired studies upon each animal.

\section{Results}

The pattern of gastric emptying was biphasic in all of the studies with the cannula closed (Fig. 3). The duration of the initial rapid phase ranged from seven to 17 minutes, and the mean amount emptied during this period was $33 \%$. After this there was complete gastric stasis until the end of the study period, except for one dog in which emptying recommenced at a



Fig. 4 Gastric emptying at 15 min is shown for each of the studies with the cannula closed. Individual variations for the duplicated studies ranged from $1 \%$ to $24 \%$ (mean $9.5 \%$ ). The overall range of emptying at $15 \mathrm{~min}$ was $12-66 \%$.

slow rate from 45 minutes onwards. The daily variation and ranges in the amounts emptied during the initial 15 minutes are shown in Figure 4. The pattern and rate of emptying were similar in dogs with and without Dacron cuff insertion.

In studies with the cannula open and without distal instillation of test solutions, initial gastric emptying was much greater than in studies with the cannula closed. The differences in the amounts emptied were statistically significant throughout the study period $(p<0.001$, Fig. 3). Analysis of the cannula effluent showed that there was less than $10 \%$ dilution of the test meal during passage through the stomach.

Distal instillation of $0.9 \%$ saline, when started at the same time as the meal was administered, had no effect on gastric emptying. Emptying in these studies was almost identical to that in studies without distal instillation of a test solution (Fig. 3).

Distal instillation of $15 \%$ dextrose, in the same fashion as saline, slowed gastric emptying. In these studies the pattern of emptying remained biphasic, but after the initial rapid phase there was a tendency to slower emptying rather than to complete stasis. The amounts emptied were significantly less throughout the study period than in corresponding studies without distal instillation. Emptying remained more rapid, however, than in studies with the cannula closed, the difference being statistically significant from 15 minutes onwards (Fig. 3).

When $15 \%$ dextrose was instilled before administration of the test meal, gastric emptying was slower than when instillation started simultaneously, the 


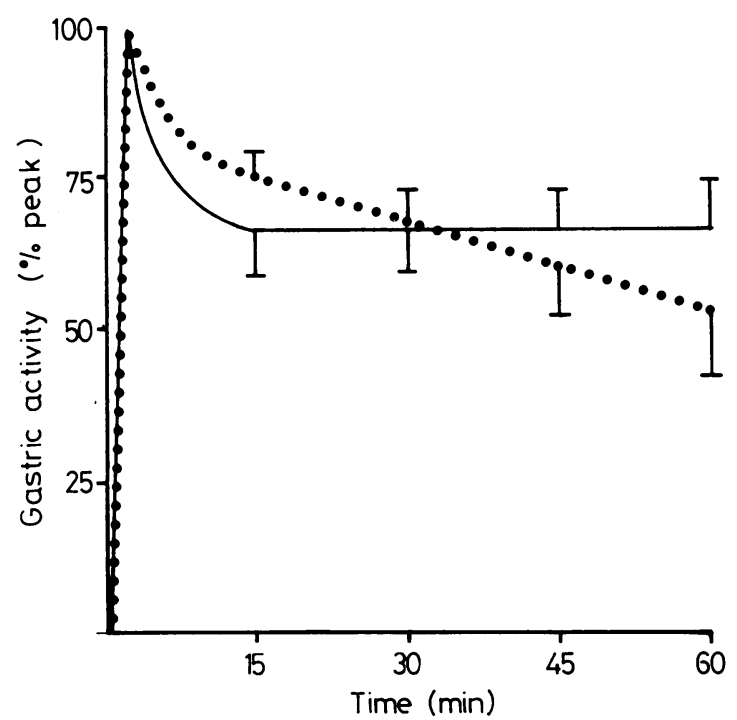

Fig. 5 Results of studies in which $15 \%$ dextrose was instilled distally before administration of the test meal ( $\cdots)$ compared with those from studies with the cannula closed (-). There were no significant differences in amounts emptied throughout the study period.

difference being significant at 15 minutes $(\mathrm{p}<0.05)$ and $30 \min (p<0.01)$. The differences between these studies and those with the cannula closed were not significant at any time during the study. There was, however, a tendency towards a more normal pattern of gastric emptying, with slower initial and subsequent linear emptying (Fig. 5).

\section{Discussion}

As expected truncal vagotomy and pyloroplasty resulted in a uniformly biphasic pattern of gastric emptying in studies with the cannula closed. This contrasts with a linear pattern of emptying seen in the vagally intact model studied using the same test meal. ${ }^{7}$ In this previous study the presence of a closed proximal duodenal cannula and periduodenal Dacron cuff were shown to have no effect on either the rate or pattern of gastric emptying. In the present study, the cannula and cuff are, therefore, unlikely to have influenced our results. During this study we abandoned the use of a periduodenal Dacron cuff, having lost two other animals to study in the late postoperative period because of cuff related sepsis. There were, however, no detectable differences in emptying in the present study between dogs with and those without a cuff. Furthermore, after testing with methylene blue, we question the necessity for cuff insertion in models of this sort. ${ }^{8}$
After the period of initial rapid emptying all animals except one exhibited gastric stasis for the remainder of the period. Presumably recommencement of gastric emptying would have been observed had studies continued beyond the hour, as all animals remained nutritionally well and vomiting did not occur at any time.

Studies with the cannula closed were repeated in order to examine daily variations in gastric emptying in this model. The variation exhibited by individual dogs was in each case much smaller than the overall variation among the group. This finding is consistent with previous reports of studies upon intact dogs and man in which similar values for day to day variability were found. ${ }^{679}$ Nevertheless, we felt that more truly representative data would be obtained by duplicating subsequent studies in order to minimise the effects of daily variations in emptying.

Our interpretation of these studies is based on the following assumptions. With the cannula closed the pattern of emptying could be influenced by a combination of small bowel resistances, osmoreceptor feed back and small bowel distension reflexes. With total diversion of effluent through the cannula emptying cannot be influenced by small bowel resistances, and if nothing is instilled distally neither small bowel osmoreceptors nor stretch receptors will be stimulated. With distal instillation of isotonic saline the small bowel will be challenged with a fluid volume similar to that attending studies with the cannula closed. Stretch receptor stimulation will thus be reproduced while osmotic stimulation is absent. Instillation of $15 \%$ dextrose in the same manner will evoke both osmoreceptor and stretch reflexes. Finally, having noted that the osmoreceptor response in the intact stomach may be mediated by a combination of humoral $^{10}$ and vagal ${ }^{11}$ pathways, we reasoned that delayed onset of osmoreceptor inhibition could explain the biphasic pattern of gastric emptying seen after this procedure. If this were so, duodenal challenge with dextrose before test meal administration might be expected to abolish the initial rapid phase. On the other hand, this manoeuvre would not be expected to influence the effect upon gastric emptying of either intrinsic gastric motility or small bowel resistances during studies with the cannula open.

In studies with diversion alone emptying was initially much greater than with the cannula closed. This shows that when released from all other influences, the canine stomach, after truncal vagotomy and pyloroplasty, empties rapidly and almost completely. Distal instillation of isotonic saline had no effect on emptying, showing that small bowel distension reflexes have no significant influence on the emptying pattern. Distal instillation of $15 \%$ dextrose, 
however, did slow gastric emptying. Thus, the osmoreceptor response was shown to persist after truncal vagotomy. This finding is in accordance with the results of previous studies upon dogs ${ }^{12}$ and man. ${ }^{13}$ In the present study, however, emptying in these circumstances remained significantly faster than in studies with the cannula closed. We may infer from this that small bowel resistances also played a significant role in the control of gastric emptying in studies with the cannula closed. When $15 \%$ dextrose was instilled before administration of the test meal, emptying was delayed further and the amounts emptied were no longer significantly different from those seen in studies with the cannula closed. This suggests that the osmoreceptor inhibition increases gradually over the period of rapid initial emptying, in contrast with the immediate response observed in previous studies on the vagally intact model. ${ }^{7}$ Interestingly, gastric stasis did not occur in studies in which duodenal instillation preceded administration of the test meal. This is in contrast with the results obtained from studies with the cannula closed, and again suggests that small bowel resistances contribute to the development of stasis.

The results of the present study indicate that the pattern of gastric emptying following truncal vagotomy and pyloroplasty in dogs is determined by the interplay of several influences. It seems likely that the operation impairs gastric reservoir function resulting in an initial phase of rapid emptying. This in turn induces small bowel resistances, which tend to oppose further rapid gastric emptying, an effect we did not observe in the vagally intact model.' The combination of small bowel resistances and an increasing osmoreceptor response produces the transition to a period of gastric stasis.

This work was supported by the Mersey Regional Health Authority Research Scheme (Number 498).

\section{References}

1 Colmer MR, Owen GM, Shields R. Pattern of gastric emptying after vagotomy and pyloroplasty. $\mathrm{Br}$ Med $\mathrm{J}$ 1973; ii: 448-50.

2 Millar JW, McLoughlin GP, MacLeod IB, Heading RC. The effect of vagotomy on the solid and liquid components of a meal. In: Duthie LH, ed. Gastrointestinal motility in health and disease. Lancaster: MTP Press, 1978: 215-21.

3 Parr NJ, Grime S, Brownless S, Critchley M, Baxter JN, Mackie CR. The relationship between gastric emptying of liquid and post-vagotomy diarrhoea. Br J Surg 1988; 75: $279-82$.

4 Wilbur BG, Kelly KA. Effect of proximal gastric, complete gastric, and truncal vagotomy on canine gastric electric activity, motility and emptying. Ann Surg 1973; 178: 295-303.

5 Clarke RJ, Alexander-Williams J. The effect of preserving antral innervation and of a pyloroplasty on gastric emptying after vagotomy in man. Gut 1973; 14: 300-7.

6 Ralphs DN, Thomson JP, Haynes S, Lawson-Smith C, Hobsley M, LeQuesne LP. The relationship between the rate of gastric emptying and the dumping syndrome. Br J Surg 1978; 65: 637-41.

7 Parr NJ, Grime JS, Critchley M, Baxter JN, Mackie CR. The mechanism of the gastroduodenal brake. Gut 1987; 28: $950-4$.

8 Miller J, Kauffman G, Elashoff J, Ohasi H, Carter D, Meyer JH. Search for resistances controlling canine gastric emptying of liquid meals. Am J Physiol 1981; 241: G403-15.

9 Chauduri T. Use of ${ }^{99 \mathrm{~m}} \mathrm{Tc}$-D.T.P.A. for measuring gastric emptying time. J Nucl Med 1974; 15: 391-5.

10 Quigley JP, Phelps KR. The mechanism of gastric motor inhibition from ingested carbohydrates. Am J Physiol 1934; 109: 133-8.

$11 \mathrm{Mei}$ N. Vagal glucoreceptors in the small intestine of the cat. J Physiol 1978; 282: 485-506.

12 Shahidullah M, Kennedy TL, Parks TG. The vagus, the duodenal brake, and gastric emptying. Gut 1975; 16: 331-6.

13 Gough JM, Jumphrey CS, Giles GR. Does osmotic control of gastric emptying persist after truncal vagotomy? Br J Surg 1981; 68: 77-80. 